\title{
EN HONDURAS DEFENDER LA VIDA ES UN PECADO. UNA ETNOGRAFÍA DE LOS DISCURSOS, PRÁCTICAS Y PELIGROS DE LA OPOSICIÓN A LA MINERÍA. NICK MIDDELDORP. COMAYAGÜELA, DISTRITO CENTRAL (HONDURAS): IMPRESIONES INDUSTRIALES, 2017. 235 PÁGINAS
}

José Luis Palma Herrera

Desde el punto de vista de la investigación universitaria, este libro aumenta conocimiento científico al escaso acervo de literatura académica dedicada al estudio de la minería en Honduras, pues, hasta la fecha, podemos mencionar solo tres trabajos universitarios han trascendido las fronteras hasta convertirse en material de consulta obligada para quien desee conocer la temática minera en este pequeño pero rico país en recursos. El primero, un estudio doctoral de The University of Tennessee, Knoxville, EE. UU. (1973); el segundo, un análisis conjunto entre la Clark University, EE. UU. y la Universidad Nacional Autónoma de Honduras (2017); y, finalmente, el libro de Nick Middeldorp de la Universidad de Wageningen, Países Bajos (2017), en el cual nos muestra por primera vez una perspectiva etnográfica donde los movimientos sociales son la base de una sociedad que lucha contra la aplicación del modelo de desarrollo basado en el extractivismo en su país $y$, concretamente, en su comunidad.

El paradigma de desarrollo extractivista es un modelo que toda nación en desarrollo debe superar, pues degradar el medioambiente para generar crecimiento económico no es ni sostenible ni rentable (CEPAL, 2015), ${ }^{1}$ en especial la minería a cielo abierto, ya que los efectos adversos de esta práctica son sociales, económicos y, principalmente, ambientales, debido a que se consumen grandes cantidades de recursos (en especial agua) de manera no renovable, simplemente para producir unas pocas onzas troy de metal precioso.

En este libro podemos encontrar citaciones de teorías y pensamientos científicos de autores de habla inglesa que en nuestra literatura académica de habla castellana no es común encontrar. Comparte con nosotros estudios y autores de diferentes partes del mundo que nos ayudan a expandir nuestra visión del impacto del modelo extractivista y los movimientos sociales que surgen de los mismos. Esto es invaluable para cualquier persona interesada en conocer o estudiar el tema 
minero y la conexión irrefutable que existe entre lo local y lo global cuando se trata de aplicar la justicia ecológica y ambiental.

Nick nos coloca en el lugar de las comunidades rurales, es decir, nos convierte en uno más del pueblo que sufre directamente el extractivismo. Esto lo logra gracias a un estudio de campo etnográfico realizado durante meses de estudio al entablar relaciones con ambientalistas, representantes de ONG, movimientos de sociedad civil, funcionarios públicos y las propias compañías mineras.

Debido al modelo de investigación etnográfica del tipo colaborativa y activista, Nick se convierte en su propio instrumento de investigación, ya que habla y participa con las partes informantes en su contexto local, con lo cual también aporta con su conocimiento y capacidad de análisis científico al logro de cambios sociales positivos. Sin embargo, al aplicar esta metodología además de proporcionarle información detallada de primera mano y servir a las comunidades desprotegidas, pone en riesgo su vida ya que se encuentra en el ojo del huracán del activismo antiminero donde un pequeño error en "el país más peligroso del mundo para el activismo ambiental" 2 conlleva a terribles consecuencias.

El libro nos muestra la línea de tiempo de cómo nace y crece el movimiento antiminero hondureño del Siglo XXI, debido a los impactos negativos en las comunidades de las primeras concesiones internacionales otorgadas por la Ley de Minería de 1998, la cual originó la minería a cielo abierto en Honduras. En esta línea de tiempo se nos presentan cada uno de los actores principales y se explican los contextos de origen, evolución y actualidad de los movimientos sociales que surgen para contrarrestar las tres concesiones mineras de cielo abierto que desde los últimos años del Siglo XX y los primeros de este Siglo XXI representan la némesis del movimiento antiminero, las cuales son; San Andrés (Copán), La Labor (Ocotepeque) y Valle Siria (Francisco Morazán).

El libro posee explicaciones muy claras y bien fundamentadas de como en su génesis, nacieron los dos principales movimientos sociales hondureños antimineros que luego se unieron en uno solo para fortalecerse y apoyarse, pero que lamentablemente por diferencias de base se separaron. Pero de esta valiosa iniciativa social florecen diferentes triunfos y experiencias que a la larga han beneficiado al activismo minero con grandes logros, tales como detener una concesión minera a cielo abierto ilegalmente concedida, la cual destruiría un área protegida, apoyar a comunidades afectadas por los químicos tóxicos mineros y finalmente, comprobar la inconstitucionalidad de una Ley Minera, hasta el punto de lograr vetar concesiones y crear un nuevo marco legal para regular más fuertemente la minería en Honduras, ya que debe tomar en cuenta la voz de las comunidades y por ende así evitar cometer las atrocidades del pasado reciente. 
También nos advierte que a pesar de los triunfos en las modificaciones legales que regulan la actividad minera actual, existen muchos vacíos jurídicos por subsanar y restricciones más fuertes por aplicar como la eliminación definitiva de la minería a cielo abierto y la prohibición total del uso de químicos en estas actividades.

Algo que debe destacarse, es la imparcialidad y ética mostrada por Nick a lo largo de todo el libro, ya que demuestra ser imparcial durante este complejo estudio donde cada lado defiende su lucha y sus ideas. Pero al estar inmerso en las situaciones que se viven día a día en esos pueblos humildes, olvidados por muchos y abandonados por todos, no deja de estar atento a identificar las injusticias cometidas a quienes no tienen voz ni voto en la definición de sus destinos, a causa de la riqueza mineral que está bajo sus pies descalzos.

En uno de sus capítulos, Nick amplía nuestra percepción sobre el ámbito minero en Honduras y nos muestra un lado oscuro y poco conocido de las atrocidades cometidas en el interior de este país. Ya que es ampliamente difundida y conocida la actividad minera de las grandes empresas internacionales que se dedican al extractivismo, pero también existen empresas mineras locales o nacionales que, aunque de menor impacto, afectan a las comunidades y su entorno natural de una manera mucho más violenta y represiva a tal punto de compararse con organizaciones criminales en lugar de empresas mineras. Con una muestra de casos de minería artesanal se nos expone como esta figura de explotación minera puede llegar a convertir a algunas regiones rurales en pequeños enclaves mineros donde las autoridades "brillan por su ausencia" y se pueden cometer cualquier clase de atrocidades contra la vida humana de quien se oponga a la minería, atrocidades que van desde el secuestro de observadores internacionales hasta el brutal asesinato de inocentes por grupos armados.

Aquí es donde donde aparecen estos grupos armados, que el uso de armas para explotar el mineral es común. Nick expone lo que muy pocos se atreven a decir, eso que callan tanto los que apoyan como los que están en contra de la minera; por ejemplo que el narcotráfico también hace extractivismo. Estos "buitres mineros" son temidos por todos a tal punto de tantos unos como otros miran para otro lado cuando se trata el tema. Nick, es el primero en mencionar este cáncer que carcome este país en un documento académico, donde desde luego, unas pocas fuentes periodísticas nacionales ya han advertido del este nuevo mal: "la narcominería".

Al terminar de leer el libro, el lector recuerda el título y entenderá que cualquier persona en Honduras que esté en contra del modelo de desarrollo extractivista tendrá algo asegurado: un castigo mortal, pues "en Honduras es un pecado defender la vida, porque quienes defienden el agua, los territorios y la forma de vivir se exponen a ser castigados" (177). 


\section{Notas}

1 CEPAL. Mejorar la gobernanza de los recursos naturales permitirá a la región avanzar hacia el desarrollo con igualdad, 2015. Recuperado de: http://www.cepal.org/es/comunicados/mejorarla-gobernanza-de-los-recursos-naturales-permitira-la-region-avanzar-hacia-el

2 Global Witness. Honduras: El lugar más peligroso para defender el planeta, 2017. Recuperado de: https://www.globalwitness.org/documents/18726/Defenders_Honduras_full_report_ Spanish_spreads.pdf

José Luis Palma Herrera. Máster en Ordenamiento y Gestión Territorial. Profesor del Departamento de Ciencia y Tecnologías de la Información Geográfica (DCTIG) de la Facultad de Ciencias Espaciales (FACES), investigador voluntario del Observatorio Universitario de Ordenamiento Territorial (OUOT) e investigador consultor de la Dirección de Investigación Científica y Posgrados (DICYP) de la Universidad Nacional Autónoma de Honduras (UNAH).

Contacto: jose.palma@unah.edu.hn y herrer@hotmail.com

ORCID: 0000-0002-3578-2714 